\title{
ХАРАКТЕРИСТИКА СОВРЕМЕННЫХ ГОРИЗОНТАЛЬНЫХ ДВИЖЕНИЙ В ЙЕНТРАЛЬНОМ СЕКТОРЕ БОЛЬШОГО КАВКАЗА ПО ДАННЫМ GPS-НАБЛЮДЕНИЙ
}

\author{
Аль Дарабсе А.М.Ф., \\ Маркова Е.В. \\ ИАТУ УлГТУ, г. Ульяновск, РФ
}

В статье освещаются результаты первых GPS-измерений, выполненных по геодезическому профилю, который пересекает все основные геологические структуры в осетинском регионе Большого Кавказа. Интерпретация результатов измерений была сделана в сравнении $c$ результатами неотектонических исследований $u$ данными о глубокой структуре. Максимальное снижение текущих скоростей поперечного сжатия было зафиксировано в области наибольшего подъема над поверхностью Земли низкокачественного объема земной коры, что оказывает расширяющее влияние на всю горную структуру. Наличие значительных поперечных смещений поверхности отражает сдвиговую составляющую вдоль крупнейших разломов Кавказского простирания. Ранее прогнозируемое значительное снижение скорости горизонтальных движений в конще афтершокового прочесса катастрофического землетрясения в Раче в 1991 году на южном склоне Большого Кавказа полностью подтвердилось.

Ключевые слова: тектоника, геодинамики, GPS, структура, земной коры, Большой Кавказ.

Большой Кавказ и его осетинский сегмент представляют собой регионы со сложной тектонической структурой. Регион также непростой из-за высокой сейсмичности, наличия опасных геологических процессов, причудливых поверхностных и подземных рельефов, разнообразного состава пород и состояния почвы, насыщенности полезными ископаемыми, отходами горных работ и высокой плотности населения. Это вызывает большой научный и практический интерес к состоянию региона и его современным тектоническим движениям [1].

Согласно тектонической концепции плит, этот регион является результатом взаимодействия двух крупных литосферных плит, евразийской и арабской. Считается, что конвергенция этих плит определяет современную геодинамику региона с продолжающимся формированием структуры складок и толчков, сложной системой разломов, вулканизмом, высокой сейсмичностью и активными движениями земной коры. Независимо от конкретной интерпретации тектонической структуры Большого Кавказа, все согласны с тем [2], что эта структура была в значительной степени сформирована субгоризонтальными, обычно перекрестными ударными сжимающими 
напряжениями. Эти напряжения остаются критическими даже на современном этапе тектонической эволюции [3], что подтверждается анализом очаговых механизмов региональных землетрясений [4].

Наиболее перспективными исследованиями современной геодинамики в активных тектонических провинциях являются комплексные исследования с использованием геодезических, геофизических, неотектонических и сейсмологических методов. В последние годы в осетинском сегменте мегантиклинория были проведены геологические, геофизические, палеосейсмологические и GPS наблюдения. Полученные результаты позволяют построить новую модель корреляции современных горизонтальных смещений земной поверхности и глубинного строения земной коры с процессами активации сейсмогенерирующих зон для этого важного с точки зрения сейсмической безопасности региона [5].

В осетинском регионе Большого Кавказа Астрономический институт им. Штернберга Московского университета совместно с ВНЦ РАН создал спутниково-геодезическую сеть, состоящую из 25 участков в режиме съемки для проведения периодически повторяющихся измерений GPS, а также непрерывную станцию для GPS наблюдения (код ВЛКК). Также использовались данные двух станций, созданных Геофизической службой PAH (коды ARDN, PRTN). Оценка скоростей современных тектонических движений основана на анализе временных рядов GPS-координат мест съемки в режиме съемки и непрерывных станций, рассчитанных по первичным данным, которые представляют собой наборы фазовых и кодовых измерений на двух частотах продолжительностью три дня с записью. интервал 30 секунд UTC + 0 (GMT). Для большинства сайтов периодичность измерений кратна одному году. Программный пакет GAMIT / GLOBK использовался для обработки данных GPS [6].

Оценка скоростей горизонтальных движений вдоль геодезического профиля, пересекающего все основные геологические структуры Большого Кавказа, проведена впервые. Это определяет необычайную ценность измерений. Для интерпретации результатов использовалась тектоническая схема, составленная на основе данных разномасштабного геологического картирования и наших собственных полевых наблюдений. Профиль расположен в зоне максимального сужения всех тектонических зон Большого Кавказа. Основные подвижные тектонические границы прямо и ярко отражены в современном рельефе и деформациях позднеплиоцен-эоплейстоценового геоморфологического уровня (рис. 1) [7].

Проекции горизонтальных скоростей смещения были экстраполированы на объединенный структурно-геоморфологический и геофизический профиль вдоль долин рек Большой Лиахви и Ардон (рис. 2). Геофизические исследования проводились методом микросейсмического зондирования (МСM), который позволяет нам адекватно идентифицировать конфигурацию как субвертикальных, так и субгоризонтальных границ скоростей на глубину 60 км [8].

У метода MS есть несколько альтернатив в мире. При всем разнообразии технологий их реализации (сейсмические массивы или одноточечные 
измерения) у всех этих подходов есть одна общая черта - тот факт, что их базовая модель формирования микросейсмического поля требует, чтобы среда была наслоена обязательно, последовательно и локально. Поэтому

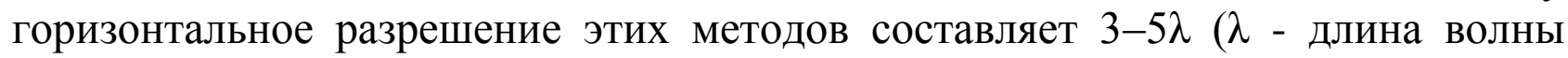
основной моды Рэлея, которая взаимодействует с неоднородностью). В отличие от этих подходов, модель формирования микросейсмического поля, принятая в МСМ, не требует наслоения среды. В связи с этим считается, что основной вклад в микросейсмическое поле вносят фундаментальные моды Рэлея, тогда как наличие высших мод минимально. Роль информативного параметра (сигнала) в методе МС играет искажение амплитудного поля, вызванное взаимодействием с неоднородностями скорости. Информация о фазе не используется [9]. Форма и глубина неоднородности оцениваются по поверхностному распределению искажений на частоте, с которой это возмущение проявляет себя.

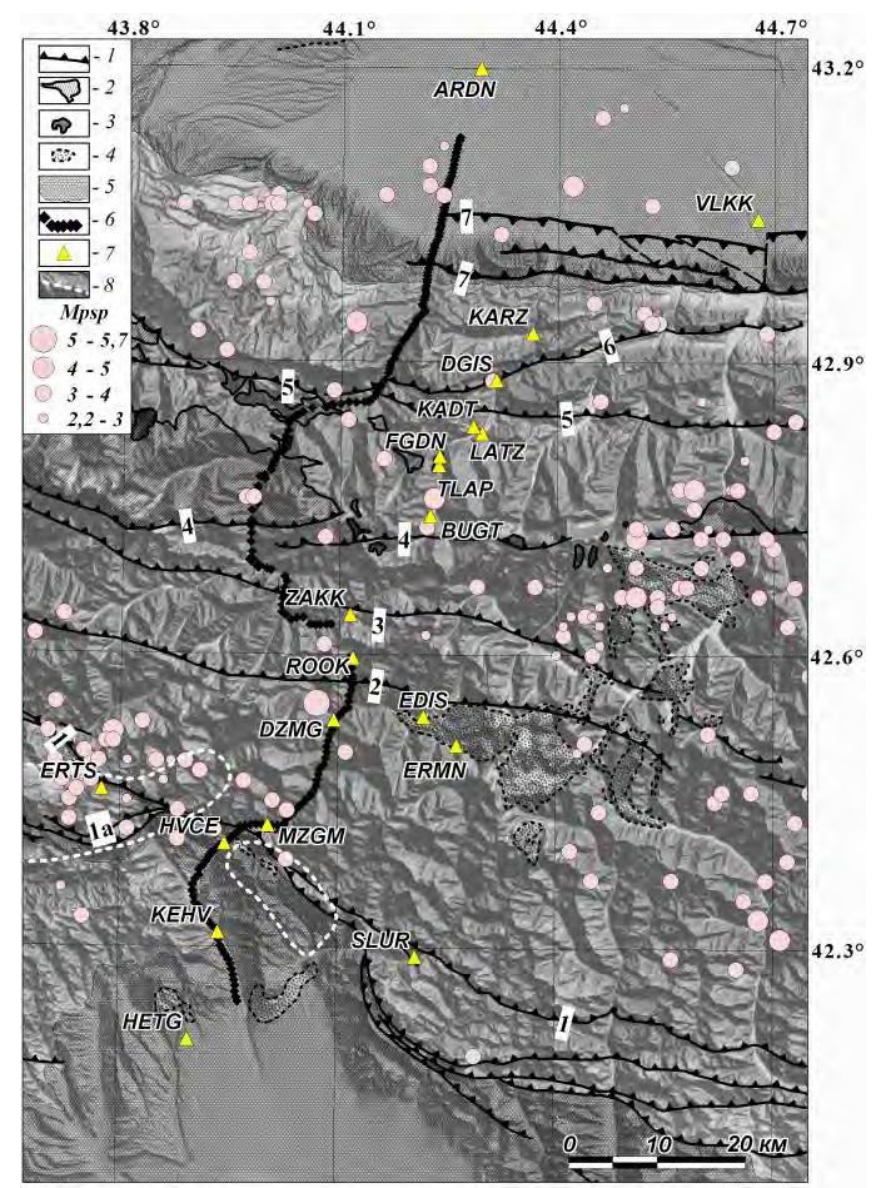

Рис. 1 Тектоническая схема района осетинской геодезической сети [11]. Круги являются эпицентрами землетрясений в 2010-2016 гг. сейсмологическая сеть Северо-Осетинского отделения Единой геофизической службы РАН

1 - основные тяги-перекрытия; 2 - выступы кристаллического фундамента; 3 плиоцен-четвертичные интрузии; 4 - плиоцен - четвертичный вулканический; 5

- олигоцен-плиоценовые отложения осетинской впадины Предкавказского прогиба, Рача-Лечхумиского прогиба и Закавказской межгорной впадины; 6 - 
пикеты профиля микросейсмического зондирования (МСM); 7 - пункты и станции осетинской геодезической сети; 8 - контуры сгущающихся полей эпицентров афтершоков землетрясений в Раче $(\mathrm{M}=7,1)$ и Яве $(\mathrm{M}=6,2)$.

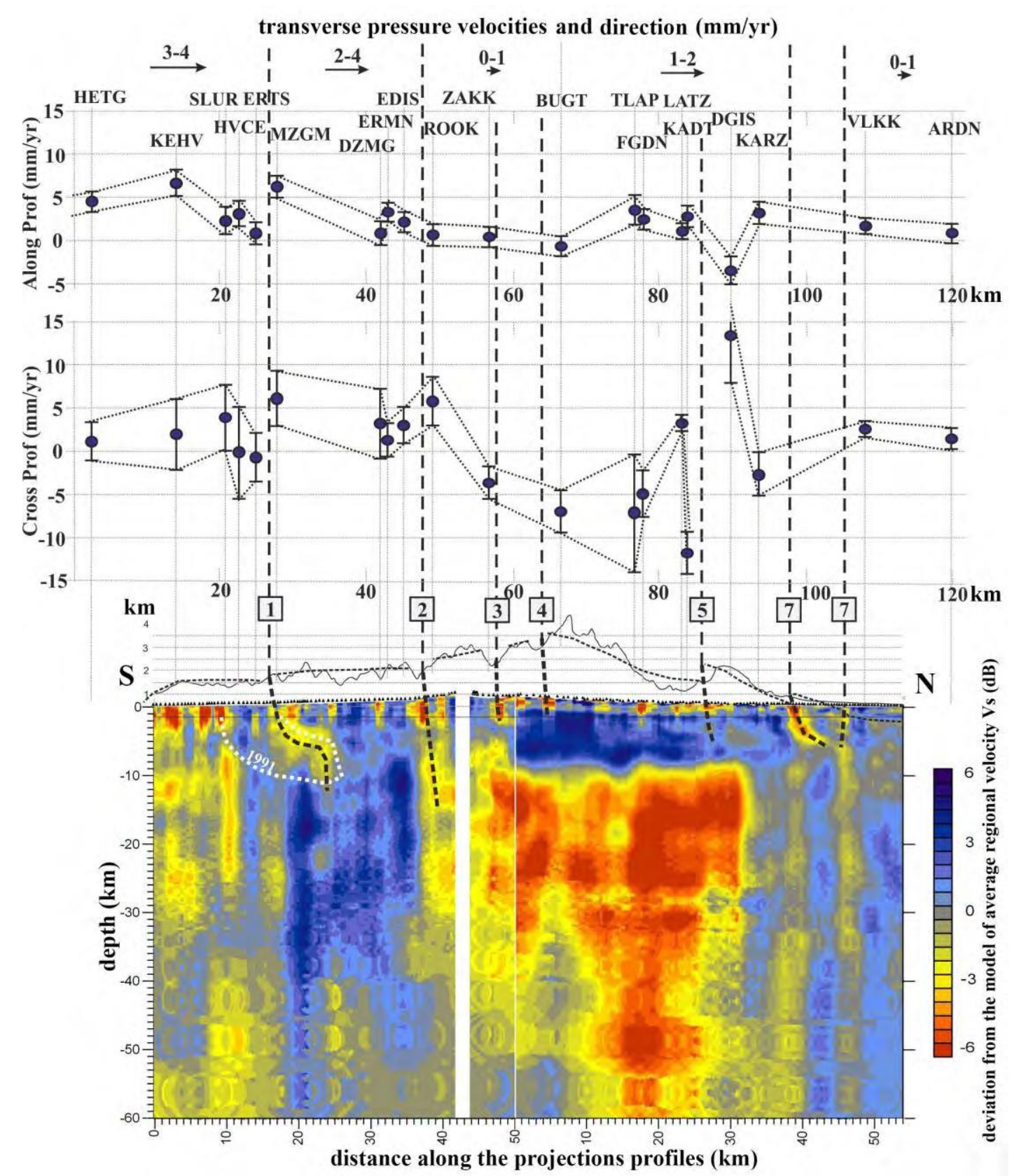

Pис. 2 Структурные геоморфологические и геофизические профили в сочетании с продольной (Вдоль проф) и поперечной (Кросс Проф) проекциями горизонтальных скоростей смещений точек и станций осетинской геодезической сети относительно фиксированной Евразии на профиле с азимутом $15,88^{\circ}$.

Горбатиков и Цуканов показали, что на поверхности Земли выше высокоскоростных неоднородностей (скорости упругих волн в неоднородности выше, чем в принимающей среде) спектральные амплитуды в определенной полосе частот уменьшаются, а выше низких В скоростных структурах (где скорости ниже, чем в принимающей среде) спектральные амплитуды 
увеличиваются. Существует критическая частота $\mathrm{f}$ волны Рэлея, для которой искажения от неоднородности, расположенной на глубине $\mathrm{H}$, являются максимальными по сравнению с аналогичными неоднородностями, расположенными на других глубинах. Эта частота $\mathrm{f}$ связана с глубиной $\mathrm{H}$ и соответствующей скоростью основной моды Рэлея VR (f) по формуле $\mathrm{H} \approx$ 0,4VR (f) / f. Это подтверждается исследованиями геологических объектов различного масштаба и происхождения, а также модельными расчетами. Это соотношение используется для обратной процедуры оценки глубины для неизвестной неоднородности, которая формирует амплитудные искажения, которые можно наблюдать на частоте f [10].

Составной профиль МСМ (рис. 2) был получен в три этапа усилиями участников экспедиции ИПЭ РАН и Центра геофизических исследований Владикавказского научного центра Российской академии наук. На первом этапе измерения проводились на участке профиля от города Ардон до северного склона Пастбищного хребта. Второй и третий этапы были реализованы в 2012 и 2013 годах соответственно. Сегмент профиля, снятый на втором этапе зондирования, закончился на южной административной границе PCOA [1]; конец третьего сегмента профиля соответствует северной границе города Цхинвал. На своем пути композитный профиль проходил через туннель Рук (Рук), где проведение измерений было технически невозможно из-за реконструкции туннеля.

Геологические объекты с относительно высокими сейсмическими скоростями появляются в микросейсмическом поле как зоны с малыми амплитудами и наоборот. В сочетании с данными о возникновении тектонических процессов в четвертичном периоде глубокий профиль МСМ дает представление об источниках современных орогенных движений. Низкоскоростное тело, обнаруженное под самой возвышенной частью Большого Кавказа, явно коррелирует с областью максимального поднятия на поздней орогенной стадии и может быть сравнено с относительно легким, низкокачественным объемом земной коры. В терминологии Д.Г. Волскова это тело можно интерпретировать как следствие глубокого диапиризма. Важно отметить, что максимальное уменьшение поперечного сжатия было зарегистрировано в области наибольшего подъема к поверхности земли с низким Q объема земной коры [3].

Существует определенная корреляция скоростей смещения, зарегистрированных вдоль и поперек геодезического профиля [8]. К югу от зоны разлома Кахетии-Лечхуми, где поверхностные движения, поперечные к Кавказской горно-складчатой структуре, имеют наибольшие значения, скорости поперечного смещения составляют 1-5 м / год. К северу, в самой возвышенной части мегантиклинория, где скорости современных смещений в направлении север-северо-восток значительно уменьшены, скорости поперечных движений, наоборот, возрастают (5-15 мм / год), а к северу от зоны Владикавказского разлома поперечные скорости снижаются до 1-3 мм / год [6].

Наличие значительных поперечных смещений поверхности вызывает 
сдвиговую составляющую вдоль крупнейших разломов Кавказского простирания. Таким образом, во время землетрясения на Яве (15.06.1991) с М = 6,2, согласно сейсмологическим (механизм источника) и геологическим и геоморфологическим данным на этом участке, сейсмогенный разлом КахетиЛечхуми был левосторонним смещением вверх [7].

Следует напомнить, что после сильнейшего землетрясения в Раче в 1991 году в эпицентральной области была расположена временная локальная сеть из пяти станций GPS. Эта сеть в течение четырех лет регистрировала горизонтальные поверхностные движения на южном склоне Большого Кавказа и на Закавказской плите. По-видимому, в этот период срединный массив Дзирул и окрибо-сачхерская зона Закавказской плиты сместились на север со скоростью 4,2 \pm 09 мм / год и непосредственно к северу от разлома КахетииЛечхуми. Смещения тектонических зон южного склона на юг и юго-юго-запад зафиксированы со скоростями 6,8 $\pm 1,2$ мм / год. Следовательно, в фокальной зоне землетрясения было зафиксировано уменьшение земной поверхности со скоростью около 1 см / год. В то же время северокавказское крыло разлома характеризовалось значительно более высокой скоростью горизонтального движения [4].

Как видно из приведенных данных, в последние годы скорость поверхностного смещения почти вдвое сократилась, а быстрые движения южного крыла мегантиклинория в южных точках исчезли. В то же время резкое уменьшение скоростей в зоне разлома Кахетии-Лечхуми, по сути, соответствует тенденции, отмеченной после землетрясения в Раче. В то же время, значительное снижение скорости горизонтальных движений в конце афтершокового процесса, предсказанное ранее исследователями, полностью подтвердилось.

Но резкое уменьшение скоростей горизонтальных поверхностных движений в зоне активного разлома Владикавказа можно интерпретировать как предвестник будущего сильного землетрясения, особенно в связи с глубоким сейсмическим затишьем в этой сейсмогенизирующей дизъюнктивной структуре.

Работа сети предназначена для разработки концепции безопасности людей, живущих в горных районах, и для разработки стандартных сценариев опасных геологических процессов (оползни, движение ледников с горными ледяными горками, землетрясения и т. д.).

\section{Список литературы}

1. Миллер В.В. Роль искусственного интеллекта в роботехнике. // В сборнике: Биотехнические, медицинские и экологические системы, измерительные устройства и робототехнические комплексы - Биомедсистемы2019 Сборник трудов XXXII Всероссийская научно-техническая конференция студентов, молодых ученых и специалистов. Под общей редакцией В.И. Жулева. 2019. С. 638-641. 
2. Аль-Дарабсе А.М.Ф. Проблемы программного обеспечения в авиационных системах. // В сборнике: Проблемы технического сервиса в АПК Сборник научных трудов II студенческой всероссийской научно-практической конференции. 2019. С. 7-15.

3. Вольсков Д.Г. Подрыв конфиденциальности в системе адресации отчетности авиационной связи. // В сборнике: Миллионщиков-2019 Материалы II Всероссийской научно-практической конференции студентов, аспирантов и молодых ученых, посвященной 100-летию ГГНТУ. 2019. С. 123-129.

4. Маркова Е.В. Система мониторинга работособности авиационных газотурбинных двигателей по реальным данным. // В сборнике: Миллионщиков-2019 Материалы II Всероссийской научно-практической конференции студентов, аспирантов и молодых ученых, посвященной 100летию ГГНТУ. 2019. С. 137-143.

5. Маркова Е.В. Особенности снабжения аэрокосмической промышленности. // В сборнике: В мире научных открытий Материалы III Международной студенческой научной конференции. 2019. С. 137-140.

6. Черненькая Е.В. Форсайт-аудит систем управления в аэрокосмической технологии. // Вестник Ульяновского государственного технического университета. 2019. № 1 (85). С. 71-73.

7. Маркова Е.В., Аль-Дарабсе А.М.Ф. Влияние инноваций на экономический рост. // Вестник Ульяновского государственного технического университета. 2019. № 2 (86). С. 72-74.

8. Аль-дарабсе А.М.Ф., Маркова Е.В. Исследование требований летной годности составных воздушных судов для воздушных судов транспортной категории в FAA. // Российский электронный научный журнал. 2019. № 1 (31). C. 8-21.

9. Денисова Т.В. Моделирование турбовинтовой гибридной электрической двигательной установки. // Российский электронный научный журнал. 2019. № 2 (32). С. 16-33.

10. Черненькая Е.В. Исследование экономических систем в авиастроении на основе методологии функционально-стоимостной инженерии. // В сборнике: Молодежь и наука XXI века Материалы Международной научной конференции. 2018. С. 470-472. 